\section{Sorologia Anti PGL-1 e risco de ocorrência de hanseníase em área de alta endemicidade do Estado de São Paulo: quatro anos de seguimento ${ }^{1}$}

\section{Anti PGL-1 Serology and the Risk of Leprosy in a Highly Endemic Area in the State of São Paulo, Brazil: Four- Year Follow-Up}

\author{
Mitie Tada L.R.F. Brasil \\ Centro de Vigilância Epidemiológica Prof. A. Vranjac \\ Secretaria de Estado da Saúde de São Paulo \\ Av. Dr. Arnaldo, 351 - $6^{\circ}$ andar \\ 01246-000 - São Paulo/SP \\ dvhansen@saude.sp.gov.br
}

\section{Luiz Roberto de Oliveira}

Departamento de Saúde Pública

Faculdade de Medicina de Botucatu - UNESP

\section{Nely S. Rímoli}

Centro de Saúde de Severínia, São Paulo.

\section{Sérgio Cavallari F.}

Centro de Vigilância Epidemiológica Prof. A. Vranjac Secretaria de Estado da Saúde de São Paulo

\section{Otília S. Gonçalves}

Centro de Vigilância Epidemiológica Prof. A. Vranjac Secretaria de Estado da Saúde de São Paulo

\section{Zenaide L. Lessa}

Centro de Vigilância Epidemiológica Prof. A. Vranjac

Secretaria de Estado da Saúde de São Paulo

\section{Osmar Rotta}

Departamento de Dermatologia

Escola Paulista de Medicina - UNIFESP

\footnotetext{
1 Parte da tese de mestrado "Estudo soroepidemiológico de Hanseníase em área de alta endemicidade no Estado de São Paulo", apresentada à Escola Paulista de Medicina (UNIFESP), em 1995
}

\section{Resumo}

Os testes sorológicos para diagnóstico de hanseníase, usando o glicolipídeo-fenólico1 (PGL-1), considerado antígeno específico do M. leprae, têm aberto algumas possibilidades de estudo do comportamento epidemiológico desta doença. Algumas questões, como tempo de latência da doença, infecção subclínica e importância do contato intra-domiciliar (contatos) no controle da endemia, puderam ser melhor analisadas usando este instrumental. Este estudo teve por objetivo verificar a existência de associação entre a situação sorológica e a ocorrência de hanseníase. Foram seguidas, durante 4 anos, 6.520 pessoas com idade igual ou superior a 5 anos, submetidas no início do seguimento ao teste sorológico Anti PGL1 , pertencentes ao universo de 7.416 habitantes da área urbana de um município paulista caracterizado por elevada endemicidade de hanseníase. Foi identificado um grupo de 590 indivíduos soropositivos $(9,0$ $\%)$. Foram diagnosticados, no período, 82 casos novos de hanseníase, 26 no grupo de soropositivos (441 casos novos/ 10.000 indivíduos) e 48 no de soronegativos (81/10.000). Entre os que não fizeram sorologia, surgiram 8 casos novos $(89 / 10.000)$. Procurou-se controlar, na análise, a condição de contato, dado que a taxa de soropositividade padronizada por idade e sexo era de $9,61 \%$ no grupo de contatos e $7,65 \%$ no de não-contatos. Tomando-se os não-contatos soronegativos como o grupo de "não expostos", foram calculados os riscos relativos de adoecimento no período, a partir das taxas de detecção padronizadas por idade, resultando no seguinte: os contatos ID soropositivos apresentaram a taxa de $1.704 / 10.000,27$ vezes maior que a dos "não-expostos", igual a 63/ 10.000; os não-contatos soropositivos e os contatos soronegativos apresentaram taxas, respectivamente, de $274 \mathrm{e}$ 198/10.000, ambas maiores que as dos "não-expostos" e iguais entre si. A soropositividade associou-se à elevação de 8,6 vezes do risco de hanseníase entre os contatos e de 4,4 entre os não-contatos. Na situação epidemiológica estudada, 
caracterizada por elevada endemicidade de hanseníase, $50 \%$ dos casos novos surgiram entre os não-contatos soronegativos, ou seja, sem fonte de infecção conhecida. Portanto, o teste anti-PGL-1 usado revela-se, na prática, de pouca aplicabilidade. Resta estudar ainda o comportamento da sorologia anti$P G L-1$ em áreas de média e baixa endemicidade para que se possa tirar conclusões mais consubstanciadas sobre sua utilidade no controle da endemia. Recomenda-se o aprofundamento das pesquisas sorológicas e de outras que aprimorem o diagnóstico precoce da infecção subclínica, inclusive para detecção de formas paucibacilares, para se ampliar as possibilidades de influir no controle endêmico.

Palavras-chave: Hanseníase. Teste antiPGL-1. Epidemiologia da hanseníase. Estudo de coortes. Taxas de detecção de hanseníase. Contatos intra-domiciliares. Sorologia da hanseníase.

\section{Abstract}

Serum tests for the diagnosis of Leprosy using Phenolic GlicoLipid-1 (PGL-1), considered a specific antigen for $M$. leprae, have opened some possibilities for studying the epidemiological behavior of this disease. Some questions, such as incubation period, sub-clinical infection and the importance of household contacts for endemic control, have been better evaluated using this technique. The present study has the objective of verifying a possible association between the serological status and the occurrence of leprosy. The authors performed a 4-year follow-up of 6,520 individuals, all of them 5 years old or over, submitted to a PGL-1 ELISA test at the beginning of the study. The group was part of the universe of 7,416 inhabitants of the urban area of a highly endemic town of the State of São Paulo. The serological research identified 590 positive individuals (9.0\%). Within this time period, 82 new cases were detected, 26 among the serum positive group $(441 / 10,000), 48$ among negatives $(81 / 10,000)$ and $8(89 / 10,000)$ among those who had not been tested. The analysis of results attempted to control for household contact status, considering that the standardized seropositive rate by age and sex was $9.61 \%$ in the contact group, and $7.64 \%$ in the non-contact group. The group of serum negatives and no household contact, the so called "non- exposure group", was adopted as reference to compute the relative risk to develop leprosy within the study period. Detection rates were standardized considering age differences between the groups and the results were: seropositive household contact rate was $1,074 / 10,000$, that is, 27 times higher than in the "non-exposure group" $(63 / 10,000)$. The detection rate in the seropositive non-household contact group was 274/10,000 and in the seronegative household contact group 198/10,000, both higher than the rate in the "non-exposure group" but similar between each other. The serum positive condition accounted for an 8.6 times higher leprosy risk in the contact group and for a 4.4 times higher risk in 
the non-contact group. In the epidemiological situation of this research, a highly endemic leprosy area, $50 \%$ of the new cases were in the non-contact seronegative group, that is, those whose infection source was unknown. So, in practice, the test revealed itself to be of little usefulness. Anti-PGL-1 serology in low and medium leprosy prevalence areas still remains to be studied in order to reach more solid conclusions on its use in leprosy control. On the other hand, further serologic and other studies are recommended in order to improve the identification of sub-clinical infection, paucibacilar forms included, so as to expand the possibility of early diagnosis and effective influence on the endemic behavior of the disease.

Keywords: leprosy; anti-PGL-1 test; leprosy epidemiology; cohort study; leprosy detection rate; household contacts; leprosy serum test.

\section{Introdução}

O diagnóstico clínico da hanseníase ainda é atividade fundamental nos programas de controle desta endemia. Seu estabelecimento na fase pré-clínica poderia causargrande impacto no controle da endemia e a meta de eliminação poderia ser mais rapidamente alcançada. $\mathrm{O}$ isolamento de um antígeno específico do M. leprae por Hunter \& Brennan ${ }^{1}$ e o desenvolvimento de testes laboratoriais para diagnóstico da hanseníase ${ }^{2,3}$ acenam com essa possibilidade. Várias tentativas foram levadas a efeito para se definirem algumas características que pudessem, com boa margem de segurança, indicar uma pessoa infectada e com elevado risco de doença. A presença de anticorpo da classe IgM, específico do M. leprae, poderia caracterizar o estado de infecção na ausência de lesões neurocutâneas.

A condição de contato intradomiciliar é a situação de risco mais estudada. Vários estudos epidemiológicos apontam para o elevado risco de hanseníase apresentado por contatos intradomiciliares ${ }^{4,5,6,7}$, sendo que as taxas de ataque são mais altas entre aqueles que convivem com pacientes portadores de formas bacilíferas.

Alguns testes foram utilizados em pesquisas para diagnosticar a infecção, como as técnicas de transformação linfoblástica, que mostraram que os contatos dos doentes apresentavam positividade em mais de $50 \%^{8}$. Outros testes, como a intradermo-reação de Mitsuda ou o antígeno solúvel de Convit et al. ${ }^{9}$, passaram a ter importância prognóstica. Estes testes, devido às limitações que apresentam, não foram adotados nas rotinas dos programas de controle.

Estudos com o phenolic glycolipid-1 (PGL-1) aplicado a grupos de risco conhecidos, como o de contatos intradomiciliares, mostram que existem percentuais variáveis de soropositividade ${ }^{10,11}$.

Com base em trabalhos publicados na época, um grupo de trabalho do Centro de Vigilância Epidemiológica Professor Alexandre Vranjac da Secretaria de Estado da Saúde de São Paulo (CVE) efetivou um inquérito 
sorológico com o teste ELISA anti-PGL-1 na população urbana com idade igual ou superior a cinco anos de um município do norte paulista dotado de elevada prevalência de hanseníase $^{12}$. A partir desse inquérito, procedeu-se o acompanhamento dessa população, procurando-se avaliar o potencial preditivo da sorologia quanto ao risco de adoecimento por hanseníase.

Este artigo refere-se ao estudo da incidência de hanseníase relacionada ao resultado da sorologia anti-PGL-1 e à condição de contato intradomiciliar.

\section{Material e Métodos}

Trata-se de um estudo populacional do tipo prospectivo controlado ou de coortes ${ }^{13,14}$ referente ao seguimento, durante quatro anos, de 1990 a 93, da população submetida à sorologia anti-PGL-1 atrás caracterizada e, inicialmente, não portadora de hanseníase. $\mathrm{O}$ critério de não-doença adotado foi o possível, ou seja, baseou-se não num exame dermatoneurológico aplicado a cada um dos indivíduos, mas tão somente na exclusão dos indivíduos com diagnóstico de hanseníase estabelecido e do conhecimento do serviço público de saúde. Todo caso novo identificado, a partir do início do acompanhamento, foi computado neste estudo.

\section{População estudada}

O projeto foi desenvolvido em Severínia, município localizado na região norte do Estado de São Paulo, dotado de alta endemi- cidade de hanseníase e onde ocorrera, em 1989, o inquérito soroepidemiológico com o teste ELISA anti-PGL-1 já mencionado ${ }^{12}$. Naquela época, a população do município era de aproximadamente 9.100 habitantes, dos quais $75 \%$ moravam na área urbana. A taxa de detecção anual de hanseníase havia sido de 27 casos novos/ 10.000 habitantes e a prevalência, em 31/12/89, de 167 casos/ 10.000 habitantes. A partir do inquérito sorológico, iniciou-se o seguimento ativo da população não doente, que somou 6.520 indivíduos com sorologia e 896 sem sorologia, distribuída segundo consta da Tabela 1.

\section{Os dados}

O censo realizado no início deste estudo forneceu os dados de população da área urbana do município e serviu também para cálculo dos coeficientes de detecção do período de 1990 a 1993.

Os dados referentes aos casos novos de hanseníase surgidos no período do seguimento foram obtidos no arquivo da Unidade de Saúde e na Divisão de Vigilância da Hanseníase do CVE. Para minimizar as perdas decorrentes do processo migratório, todos os casos de hanseníase no Estado de São Paulo, no período do seguimento, foram conferidos com o banco de dados da pesquisa, na tentativa de resgatar indivíduos sorotestados e que vieram a adoecer em outra região. Foram excluídos os casos e pessoas que imigraram para a cidade após a realização do censo e do teste sorológico.

Tabela 1 - População geral com idade igual ou maior que cinco anos e residente na área urbana, distribuída segundo a participação na sorologia anti PGL-1 e a condição de contato intradomiciliar. Severínia, SP, 1990.

Table 1 - Population of the urban area, five years of age or older, according to participation in the PGL-1 serology and household contact condition. Severínia, SP, 1990.

\begin{tabular}{|c|c|c|c|}
\hline \multirow[t]{2}{*}{ Sorologia } & \multicolumn{2}{|c|}{ Contato Intradomiciliar } & \multirow[t]{2}{*}{ Total } \\
\hline & Sim & Não & \\
\hline REALIZADA & 631 & 5.889 & 6.520 \\
\hline NÃO REALIZADA & 48 & 848 & 896 \\
\hline TOTAL & 679 & 6.737 & 7.416 \\
\hline
\end{tabular}




\section{Período}

O período deste estudo foi de 01/01/1990 a 31/12/1993, o que corresponde a quatro anos de seguimento.

\section{Sorologia}

O teste sorológico adotado foi o ELISA anti-PGL-1, segundo o método descrito por Laferte et al. ${ }^{15}$, desenvolvido em Cuba, e que se denomina ultra micro ELISA. O limiar de reatividade adotado para este estudo foi de 0,300 . Neste limiar, a sensibilidade do teste foi de $45,2 \%$ e a especificidade foi de $99,1 \%$ para todas as formas clínicas ${ }^{16}$.

\section{Seguimento}

Chama-se de seguimento ativo da população não-doente o trabalho desenvolvido pela equipe da Unidade Básica de Saúde local (UBS), supervisionado pela Divisão de Hanseníase do CVE e caracterizado por: convocação dos soropositivos para consulta médica anual; pesquisa nos arquivos do CVE; realização de atividades educativas, periodicamente, junto à comunidade. Os resultados da sorologia foram entregues aos interessados e as pessoas soropositivas foram convidadas a comparecer à UBS, em datas previamente agendadas, para se submeterem ao exame dermatoneurológico. Para a realização dessas consultas médicas, a UBS permaneceu aberta todos os sete dias da semana. Isso facilitou o acesso dos que se encontravam trabalhando. Fora desta fase de convocação, a UBS permaneceu atuante, com atendimento diário do Programa de Controle da Hanseníase e ações educativas periódicas, como exame de escolares, palestras e visitas domiciliares no restante do ano. Foram realizadas campanhas educativas todos os anos, de forma intensiva, procurando-se manter o interesse da comunidade em relação ao problema. Como o comparecimento decorrente das convocações foi pequeno nos dois primeiros anos, substituiuse este sistema pela ênfase nas atividades rotineiras de controle e, também, na divul- gação pelos meios de comunicação de massa e nas visitas domiciliares. Houve um período de seis meses de descontinuidade, durante o ano de 1992, quando o serviço ficou sem médico para atender o programa. As pessoas consideradas negativas receberam o resultado do teste, com explicação sobre o seu valor e a ressalva de que o resultado negativo não asseguraria ausência de doença, nem mesmo garantia de imunidade contra a hanseníase. Foram orientadas, também, sobre os sinais e sintomas da doença e a necessidade de procura da UBS, na vigência de qualquer sinal suspeito.

\section{Definição das coortes}

A exposição, para fins de análise dos resultados, foi definida como: ser contato intra-domiciliar de doente de hanseníase (contato ID) e ter sorologia anti-PGL-1 positiva (soropositivo), isolada ou combinadamente. Não-exposição significa: não ser contato intra-domiciliar (não-contato $I D$ ) e ter sorologia negativa (soronegativo). A coorte de não expostos seria, hipoteticamente, isenta tanto da transmissão intra-domiciliar da doença, como do contato/infecção com o bacilo, no início do seguimento. Definiu-se contato ID como sendo "toda pessoa que residisse no mesmo domicílio de um doente de hanseníase no momento de seu diagnóstico". Para identificação daquela condição, foram utilizados os dados do censo inicial e os registros das fichas de notificação do Sistema de Vigilância Epidemiológica e prontuários clínicos da UBS. Os contatos ID constaram do banco de dados da investigação com códigos específicos, que permitiam saber a forma clínica do caso índice e ano do diagnóstico. Constituíram-se, assim, quatro coortes para a observação e análise: coortes expostas (não-contato ID soropositivo, contato ID soronegativo e contato ID soropositivo) e coorte não-exposta (nãocontato ID soronegativo).

\section{Análise}

Como medida de ocorrência da hanse- 
níase, foram calculadas as taxas de detecção das coortes segundo a seguinte fórmula:

[(casos novos diagnosticados no período $\div$ número de componentes da coorte) $\mathrm{x}$ 10.000],

sendo os valores calculados para o período de quatro anos.

Como medida de associação entre a condição prévia (exposição) e o risco de adoecimento (taxa de detecção), calculouse o risco relativo, definido pela relação:

[ taxa de detecção da coorte exposta $\div$ taxa de detecção da coorte não exposta]

Os dados foram processados em microcomputador, usando-se banco de dados padrão Dbase e os programas Epi-Info e Dbscan para analisá-los. A análise da magnitude e significância dos riscos encontrados foi feita mediante o cálculo do intervalo de confiança de $95 \%$.

\section{Resultados}

Os casos novos detectados entre 1990 a 1993 resultaram do exame dos soropositivos convocados, do exame sistemático dos contatos intradomiciliares de doentes de hanseníase registrados no programa de controle da endemia e, também, da apresentação espontânea de pacientes. A taxa total de detecção no período estudado foi de 110,6 casos novos por 10.000 habitantes.
Detecção de casos e situação de contato

Dos 679 contatos IDidentificados no início do seguimento, diagnosticou-se a doença em 22, no período de quatro anos, resultando numa taxa de detecção de 342,0 casos novos por 10.000 contatos; no grupo de nãocontatos surgiram 60 casos, resultando numa taxa de detecção de 89,1 casos novos por 10.000; estes dois riscos são diferentes entre si, sendo que o contato ID responde pela elevação de 3,64 do risco de hanseníase no período de seguimento (Tabela 2). Cabe ressaltar que este risco diferenciou-se quanto à forma clínica do caso índice, chegando ao valor próximo de 7,0 no caso dos multibacilares.

\section{Detecção de casos entre os sorotestados}

Dos 82 casos novos detectados durante os quatro anos de seguimento, 74 pertenciam ao grupo submetido ao teste sorológico no início do estudo. O risco de adoecimento dos soropositivos foi de 440,7 casos novos por 10.000, taxa esta 5,4 vezes maior do que a dos soronegativos. (Tabela 3) Cabe informar, adicionalmente, que a distribuição destes casos novos, segundo a forma clínica foi: 29,7\% indeterminados; $23,0 \%$ tuberculóides; $39,2 \%$ dimorfos; e $8,1 \%$ virchowianos.

\section{Detecção de casos e as combinações entre contato-ID e sorologia}

Para esta análise, foram considerados os

Tabela 2 - Casos novos de Hanseníase e respectivos coeficientes de detecção (casos por 10.000 habitantes), distribuídos segundo a condição de contato intradomiciliar . Severínia-SP, 1990-93.

Table 2 - New leprosy cases and detection rates (cases per 10,000 inhabitants) according to household contact condition. Severínia, SP, 1990-93.

\begin{tabular}{lccccc}
\hline Contato ID & População & Doentes & $\begin{array}{c}\text { Taxa de } \\
\text { Detecção }\end{array}$ & $\begin{array}{c}\text { Risco } \\
\text { Relat. }\end{array}$ & (IC 95\%) \\
\hline SIM & 679 & 22 & 324,0 & 3,64 & $(2,25-5,89)$ \\
NÃO & 6.737 & 60 & 89,1 & 1,00 & - \\
\hline TOTAL & 7.416 & 82 & 110,6 & - & - \\
\hline
\end{tabular}


Tabela 3 - Casos novos de hanseníase e respectivos coeficientes de detecção (casos por 10.000 habitantes) distribuídos segundo resultado prévio da sorologia anti PGL-1. Severínia -SP, 1990-93.

Table 3 - New Leprosy cases and detection rates (cases per 10,000 inhabitants) according to anti PGI-1 results. Severínia-SP, 199093.

\begin{tabular}{lccccc}
\hline Sorologia & $\begin{array}{c}\text { População } \\
\text { (indivíduos) }\end{array}$ & $\begin{array}{c}\text { Doentes } \\
\text { (c. novos) }\end{array}$ & $\begin{array}{c}\text { Taxa de } \\
\text { Detecção }\end{array}$ & $\begin{array}{c}\text { Risco } \\
\text { Relat. }\end{array}$ & (IC 95\%) \\
\hline POSITIVA & 590 & 26 & 440,7 & 5,44 & $(3,40-8,71)$ \\
NEGATIVA & 5.930 & 48 & 80,9 & 1,00 & - \\
\hline REALIZADA & 6.520 & 74 & 113,5 & - & - \\
\hline
\end{tabular}

contatos e não-contatos ID com idade a partir dos 5 anos, visto que a sorologia foi realizada nesta faixa etária. As taxas padronizadas de soropositividade observadas foram de: $9,61 \%$ para o grupo de contato IDe $7,65 \%$ para o de não-contato $I D^{12}$.

A taxa de detecção entre os não-contatos soronegativos , coorte não exposta, foi de 62,6 casos novos por 10.000 indivíduos , no período de seguimento, o menor valor dentre todos (Tabela 4). A maior taxa de detecção foi observada no grupo de contatos soropositivos, atingindo-se o valor de $1.704,3$ por 10.000 indivíduos, o que representou um risco de adoecimento 27 vezes maior que o do grupo não exposto. Entre estes dois valores extremos encontram-se os riscos dos dois outros grupos de exposição: os não-contatos soropositivos, com
273,8 casos novos por 10.000 e os contatos soronegativos, com 197,7 casos novos por 10.000, ambos iguais entre si e de 2 a 6 vezes, aproximadamente, maiores que o dos nãoexpostos.

\section{Discussão}

A proposta de seguimento de uma população para se avaliar a associação das condições prévias de contato ID e sorologia com a incidência de hanseníase encontrou sérias dificuldades, pelo elevado custo/benefício que representaria a realização de censos dermatoneurológicos periódicos. Mesmo contando com a facilidade oferecida pelo funcionamento da UBS nos finais de semana, as extensas jornadas de trabalho dos habitantes, inclusive aos sábados, e a sazona-

Tabela 4 - Casos novos de hanseníase e respectivos coeficientes de detecção (casos por 10.000 habitantes), distribuídos segundo a condição prévia de contato intradomiciliar e resultado da sorologia Anti-PGL-1, Severínia-SP, 1990-93.

Table 4 - New Leprosy cases and detection rates (cases per 10,000 inhabitants), according to household contact condition and anti -PGL-1 serological results, Severínia-SP, 1990-93.

\begin{tabular}{lcccrc}
\hline $\begin{array}{l}\text { Contato ID } \\
\text { sorologia }\end{array}$ & $\begin{array}{c}\text { População } \\
\text { (indivíduos) }\end{array}$ & $\begin{array}{c}\text { Doentes } \\
\text { (c. novos) }\end{array}$ & $\begin{array}{c}\text { Taxa de } \\
\text { Detecção }\end{array}$ & $\begin{array}{r}\text { Risco } \\
\text { Relat. }\end{array}$ & (IC 95\%) \\
\hline CONTATO POSITIVO & 60 & 10 & 1704,3 & 27,05 & $(21,07-34,73)$ \\
CONTATO NEGATIVO & 571 & 11 & 197,7 & 3,14 & $(2,37-4,17)$ \\
NÃO-CONTATO POSITIVO & 530 & 16 & 273,8 & 4,35 & $(3,31-5,71)$ \\
NÃO- CONTATO NEGATIVO & 5359 & 37 & 62,6 & 1,00 & - \\
\hline TOTAL & $6520^{\text {(b) }}$ & $74^{(c)}$ & $113,45^{(\mathrm{d})}$ & - & - \\
\hline
\end{tabular}

(a) Taxa de detecção padronizada por idade para a população mundial da OMS (Pereira, 1995)

(b) Excluídos 48 contatos ID e 848 não-contatos ID, todos sem sorologia.

(c) Excluídos 1 caso novo de contato ID e 7 casos novos de não-contatos sem sorologia.

(d) A taxa de detecção total no período, sem as exclusões mencionadas, é de 110,57 casos novos /10.000 habitantes. (Ver Tabela 2) 
lidade da oferta de trabalho na região, obrigando a longos deslocamentos, apresentaram-se como outros fatores impeditivos. Essa fase apresentou maiores dificuldades operacionais do que a fase do censo sorológico, conforme descrito em Brasil et al. ${ }^{12}$. Com o decorrer do tempo, a característica insidiosa da doença, a ausência de letalidade imediata, a falta de opção profilática e o tratamento prolongado contribuíram também para o desinteresse da comunidade. Acredita-se, contudo, que a divulgação intensa e periódica dos sinais e sintomas pelos meios de comunicação disponíveis, como rádio, jornal e televisão, além do trabalho junto aos escolares e professores, igrejas e outros, permitiu alcançar os altos níveis de detecção no intervalo estudado. A avaliação dos resultados deste estudo deve levar em conta estas razões.

As perdas que ocorreram durante o período de seguimento e que não puderam ser quantificadas prejudicam a avaliação dos indicadores epidemiológicos. No entanto, vale apontar os resultados encontrados, bastante próximos de outros autores, principalmente na situação de contato.

Considerando apenas a situação de contato ID, observaram-se as seguintes taxas de detecção: 148,6 casos novos por 10.000 contatos de doentes paucibacilares (PB), de 533,8 entre os contatos de doentes multibacilares (MB) e de 92,3 entre os não-contatos. Portanto, o risco de adoecimento elevou-se 1,9 vezes pelo contato com doentes $\mathrm{PB}$ e 5,7 vezes com os MB. Estes achados são semelhantes aos de outros estudos ${ }^{4,7}$.

Ao que tudo indica, o foco intradomiciliar tem grande importância na manutenção da transmissão em áreas de baixa detecção e prevalência de hanseníase. No entanto, em áreas de alta endemicidade, como a presente, fontes de infecção indeterminadas respondem pela manutenção de altas taxas gerais de incidência de doença ${ }^{7}$. No presente estudo, foram detectados 60 casos no grupo de nãocontatos ID e 22 no de contatos ID, mesmo o risco de adoecer sendo 3,8 vezes maior neste último; constata-se, portanto, que a ocorrência de casos na população geral é suficiente para manter altos níveis de transmissão.

Outros estudos, realizados na Venezue$\mathrm{la}^{17}$ e no Rio de Janeiro ${ }^{18}$, que utilizaram sorologia em contatos observaram maior incidência de casos entre os soropositivos, semelhantemente ao ocorrido neste estudo. O risco de adoecimento 27 vezes maior entre contatos soropositivos em relação aos nãocontatos soronegativos foi elevado, porém não tanto quanto o encontrado na Venezuela $^{17}$, igual a 40 . Tem-se que considerar, neste ponto, que a Venezuela é considerada área de baixa endemicidade, ao contrário de Severínia. As soropositividades de 9,61\% entre os contatos e de $7,65 \%$ entre os não-contatos encontradas neste município são semelhantes às encontradas por Soebone \& Klatser ${ }^{19}$. Por outro lado, Fine et al. ${ }^{20}$ não relataram estas diferenças entre contatose nãocontatos, da mesma forma que os estudos realizados na Índia ${ }^{21}$, na Nova Guiné ${ }^{23}$ e na Polinésia Francesa ${ }^{22}$, o que teria levado estes autores a cogitar que, possivelmente, em áreas de alta endemicidade o risco de infecção seria semelhante entre os dois grupos.

A condição de soropositividade isolada respondeu pela elevação de 4,4 vezes no risco de adoecer de não-contatos e de 8,6 vezes no de contatos. Portanto, estes dados informam que a positividade sorológica anti-PGL1 , no contexto epidemiológico e operacional deste estudo, representou a condição prévia associada aos maiores riscos, globais e específicos, de adoecimento por hanseníase, revelando, também, um considerável poder discriminatório do risco de adoecer apresentado pela condição de contato ID.

Os autores de alguns estudos populacionais que não demostraram haver diferença no risco de adoecimento relacionado à soropositividade avaliaram que o teste PGL1 não apresentava utilidade visível nas atividades de controle ${ }^{24,25}$. Outros autores, diante das diferenças de risco encontradas, questionaram se a soropositividade de fato refletiria a infecção subclínica, mesmo diante das elevadas especificidades apresentadas pela maioria dos testes ${ }^{19}$.

É importante ressaltar, contudo, que este estudo, apesar de não ter validado o uso da 
sorologia como instrumento eficiente nas atividades de controle, acrescenta alguns subsídios para o programa de controle da hanseníase em áreas de alta endemicidade, onde toda a comunidade deveria ser tratada como em situação de contato, devendo-se adotar medidas diferenciadas que não se restringissem apenas ao domicílio do doente no momento do diagnóstico. Esta conduta viria dar mais efetividade ao programa de controle, sem contudo desconsiderar a condição de contato como a de maior risco de transmissão.

$\mathrm{Na}$ falta de medida profilática mais eficaz do que a vacina BCG-ID, a proposta de se dar grande ênfase a ações educativas aliadas à melhor oferta de serviços de saúde, com acesso facilitado e com resolutividade, ainda se constitui na principal arma disponível para o controle da hanseníase. Mesmo que existisse um instrumento de diagnóstico altamente sensível e específico, de baixo custo, padronizado e disseminado, ainda se estaria na dependência de um sistema de saúde dotado, na prática, de acessibilidade universal e boa qualidade.

\section{Agradecimentos}

Mary Lise C. Marzliack, Tanya E. Lafratta, Wagner Nogueira, Diltor Opromolla, Clóvis Lombardi, à equipe de saúde de Severínia, à DIR de Barretos e, especialmente, à comunidade de Severínia - SP pela expontânea adesão e apoio a este trabalho.

\section{Referências}

1. Hunter SW, Brennan, PJ. A novel Phenolic Glycolipid from Mycobacterium leprae. Possible involved in immunogenicity and pathogenicity. J Bacteriol 1981; 147(3): 728-35.

2. Abe M, Minagawa F, Yoshino Y, Ozawa T et al. Fluorescent leprosy antibody absorption (FLA-ABS) test for detecting subclinical infection with $M$. leprae. Int J Lepr Other Mycobact Dis 1980; 48(2): 109-19.

3. Cho S, Yanagira DL, Hunter SW, Gelber RH et al. Serological specificity of phenolic glycolipid-1 from Mycobacterium leprae and use in serodiagnosis of leprosy. Infect Immun 1983; 41(3): 1077-83.

4. Doull JA, Guinto RS, Rodrigues JL, Bancroft H. The incidence of leprosy in Cordova and Talisay, Cebu, P.I. Int J Lepr other Mycobact Dis 1942; 10: 107-31.

5. Domingues EM. Epidemiological information on leprosy in the Singu area of upper Burma. Bull World Health Organ 1980; 58: 51-90.

6. Noordeen Sk. The Epidemiology of Leprosy in: Hastings SRC (ed). Leprosy. $1^{\text {a }}$ ed. New York: Churchill Livingstone; 1985. p. 15-30.

7. Jesudasan K, Bradley D, Smith PG, Christian M. Incidence rates of leprosy among household contacts of “primary cases". Indian J Lepr 1984; 56(3): 600-14.

8. Godal T \& Negassi K. Subclinical infection in Leprosy. Br Med J 1973; 3: 557-9.

9. Convit J, Pinardi ME, Rojas FA, Gonzales I et al. Tests with three antigens in Leprosy - endemic and non endemic areas. Bull World Health Organ 1975; 52: 193-8.
10. Menzel S, Harboe M, Bergsvik H, Brennan PJ. Antibodies to a synthetic analog of phenolic glycolipid1 of $M$. leprae in the healthy household contacts of patients with leprosy. Int J Lepr Other Mycobact Dis 1987; 55: 617-25.

11. Agis F, Schilich P, Cartel JL, Guidi C, Bach AM. Use of anti $M$. leprae Phenolic glycolipid-1 antibody detection for early diagnosis of prognosis of leprosy. Int $J$ Lepr Other Mycobact Dis 1988; 56(4): 527-36.

12. Brasil MTLRF, Oliveira LR, Mello CS, Nakamura P et al. Aplicação do teste ELISA anti PGL-1 em localidade com alta endemicidade de hanseníase na região norte do Estado de São Paulo. Hansen Int 1998; 23(2): 35-48.

13. Pereira MG. Epidemiologia: Teoria e Prática. Rio de Janeiro: Guanabara-Koogan; 1995. p. 299-306.

14. Rothman KJ, Greenland S. Modern Epidemiology (2 ${ }^{\text {nd }}$ Ed). USA: Lippincott-Raven Publishers; 1998. p. 79-91.

15. Laferte J, Abreu EG, Robaina R, Verez V. Ultramicroelisa para la detección de anticuerpos IgM anti M. leprae. Rev Inst Med Trop Sao Paulo 1991; 3(6): 491-5.

16. Brasil MTLRF, Oliveira LR, Mello CS, Nakamura P et al. O Estudo da sensibilidade e especificidade do teste ELISA Anti PGL-1 no Estado de São Paulo. Hansen Int 1997; 22(2): 35-43.

17. Ulrich M, Smith PG, Sampson C, Zuniga M et al. IgM antibodies to native phenolic glycolipid-1 in contacts of leprosy patients in Venezuela: epidemiological observations and a prospective study of the risk of leprosy . Int J Lepr Other Mycobact Dis 1991; 59: 405-15. 
18. Saad MHF, Medeiros MA, Gallo MEN, Gontijo PP et al. IgM immunoglobulins reacting with the phenolic glycolipid-1 antigen from $M$. leprae in sera of leprosy patients and contacts. Mem Inst Oswaldo Cruz 1990; 85(2): 191-4.

19. Soebono H, Klatser PR. A seroepidemiological study of leprosy in high and low endemic villages. Int J Lepr Other Mycobact Dis 1991; 59: 416-25.

20. Fine PEM, Ponninghaus VM, Burgess P, Clarkson JÁ et al. Seroepidemiological studies of leprosy in Northern Malawi, based on enzyme-linked immunosorbent assay using synthetic glyco-conjugate antigen. Int $J$ Lepr Other Mycobact Dis 1988; 56: 243-54.

21. Krishnamurthy P, Rao PS, Reddy BN, Subramanian M et al. Seroepidemiological study of leprosy in a highly endemic population of South India based on ELISA using synthetic PGL-1. Int J Lepr Other Mycobact Dis 1991; 59(3): 426-31.
22. Chanteau S, Glaziou P, Plichart C, Luqiad P et al. Low predictive value of PGL-1 serology for the early diagnosis of leprosy in family contacts: results of a 10 year prospective field in French Polynesia. Int $J$ Lepr Other Mycobact Dis 1993; 61(4): 533-41.

23. Bagshawe AF, Garsia RJ, Baumgart K, Astbury L. IgM serum antibodies to phenolic glycolipid-1 and clinical leprosy: two years observation in a community with hyperendemic leproy. Int J Lepr Other Mycobact Dis 1990; 58(1): 25-30.

24. Groenen G, Pattyn SR, Ghys P, Tshilumba K et al. Yalisombo Study Group. A longitudinal study of incidence of leprosy in a hyperendemic area in Zaire with special reference to PGL-1 antibody results. Int $J$ Lepr Other Mycobact Dis 1990; 58(4): 641-50.

25. Baumgart KW, Britton MJ, Mullins RJ, Basten A et al. Subclinical infection with Mycobacterium leprae - a problem for leprosy control strategies. Trans $R$ Soc Trop Med Hyg 1993; 87(4): 412-5.

Recebido em: 07/11/2000 Versão final reapresentada em: 26/03/2003

Aprovação em: 04/06/2003 